\title{
Numerical Hydrodynamics-Based Design of an Offshore Platform to Support a Desalination Plant and a Wind Turbine in Egypt
}

\author{
Islam Amin ${ }^{1,5}$, Mohamed E.A. Ali ${ }^{2}$, Seif Bayoumi ${ }^{3}$, Ahmed Balah ${ }^{4}$, Selda Oterkus ${ }^{5}$, Hosam Shawky ${ }^{2}$ and Erkan \\ Oterkus ${ }^{5, *}$ \\ 1 Department of Naval Architecture and Marine Engineering, Port Said University, Egypt \\ 2 Desert Research Centre, Egypt \\ 3 Arab Academy for Science, Technology and Maritime Transport, Egypt \\ ${ }^{4}$ Irrigation and Hydraulics Department, Ain Shams University, Egypt \\ 5 Department of Naval Architecture, Ocean and Marine Engineering, University of Strathclyde, UK \\ *Corresponding author: erkan.oterkus@ @strath.ac.uk; Tel.: +44-141-548-3876
}

\begin{abstract}
Motivated by soial and environmental reasons, water scarcity has become a global top agenda item. Egypt is one of the countries suffering from an acute shortage of freshwater. A promising novel and efficient solution to overcome Egypt's freshwater shortage, especially in remote coastal areas far from the national grid of freshwater and electricity, is a mobile floating desalination plant (FDP) powered by offshore renewable energy. The proposed new FDP concept powered by an offshore wind turbine needs a special floating platform to provide enough buoyancy to support the weight of the desalination plant and to restrain the six degrees of freedom motions within an acceptable operational limit for a wind turbine. Based on hydrodynamics, the main objective of this study is to select the suitable offshore platform that can meet the novel FDP concept operation's requirements at a specific deployment location in Egypt. Determining the safe natural frequencies zone necessitates taking into account the new FDP concept operation constraints and the Egyptian environmental loads to select platform far from the dynamic amplifications responses in the structure. Numerical modelling results show that the cylindrical platform with a heave plate configuration demonstrated the best dynamic and static performance for Egypt.
\end{abstract}

Keywords: floating desalination plant; offshore renewable energy systems; offshore wind turbine; offshore platform; hydrodynamics of offshore platform.

\section{Introduction}

As the massive increase in the global population and the growth of economies create an increasing demand for freshwater, water scarcity has become a major problem in the world [1]. Based on the World Water Development Report of United Nations, 3.7 billion people are directly impacted by water shortages. In 2050, this figure could grow by 5.7 billion [2]. Desalinating seawater is a promising alternative for freshwater natural sources and it has been widely applied across the world. Egypt, which has the third-largest population in Africa, has been suffering for a few years from an acute shortage of fresh and clean water. The current water shortage in Egypt is 13.5 billion cubic meters per year (BCM/yr), and with the rapid increase in population, is expected to grow to 26 BCM/yr by 2025 [3]. Egypt's Ministry of Environment Affairs implies that $95 \%$ of the Egyptian population is concentrated within the area between the Nile Valley and the delta, corresponding to 
just $5.3 \%$ of Egypt's land mass area, which increases the deprivation of remote and coastal areas [4]. The rapid increase in population and limited clean water supplies urged the Egyptian government to implement water desalination programmes to compensate for the lack of freshwater, especially in remote coastal cities. A number of new conventional land-based desalination plants were established in Egypt to cover the gap between water demands and available water resources. However, the plants need a high amount of energy and a huge capital investment as they create an exhausting running cost since they are mostly operated by fossil fuels [5]. Installing high-capacity conventional desalination plants powered by fossil fuel can lead to an increase in air pollution and greenhouse gas emissions [6]. Recently, renewable energy sources such as PV panels have been implemented in desalination systems, but they have low efficiency, small capacity scale and require a large settlement area. Most of Egypt's coastal cities lack land area and therefore constructing PV systems could be costly. Moreover, most of the remote coastal areas are not connected to the national grid of water and power supply. For this reason, a mobile FDP concept powered by offshore renewable energy is standing as an efficient innovation solution around Egypt's remote coastal areas.

Compared to land-based desalination plants, an FDP powered by fossil fuel or renewable energy is a relatively young technology. For industrial projects, a range of modern FDP designs powered by fossil fuel and nuclear power have been produced and successfully evaluated. For example, Chouaki proposed a floating desalination ship powered by liquefied natural gas (LNG) for the western Mediterranean Sea [7-8]. Also, Fadel discussed the FDP concept powered by fossil fuel and compared it with conventional land-based plants [9]. The paper introduced a fully seagoing desalination vessel called RUMAITH in Abu Dhabi. The vessel contains two $1250 \mathrm{~m}^{3} /$ day thermal distiller systems powered by two diesel generators. The vessel is also equipped with full marine and navigation facilities. Many other research works investigated an FDP powered by nuclear power especially in Russia and the Mideast [10-12]. Babu introduced the design concept of floating nuclear plants [11]. According to his analytical study, five different concepts were inspired from the oil and gas industry, namely, the floating ship form hull, the floating submarine hull, the bottom caisson, artificial islands and a barge-mounted plant. The study concluded that for technological and economic factors, the floating barge designs were a much better concept. In 2017, MIT conducted another review of the hull shapes for an offshore nuclear power station. This study investigated the advantages and disadvantages of different platforms that the offshore nuclear plants could use in an effort to identify an optimal balance between the hull configuration and stability. Multiple platform designs were evaluated to compare the differences in seakeeping and stability such as cylinder, octagonal, and oval platform shapes.

There is a vast number of possible offshore platform configurations in the marine industry such as semi-submersibles, barges and spars based on the extensive experience of professionals in the oil and gas sector [13]. The initial selection of any platform type has to be based on various factors serving the FDP design targets. In the case of the present novel mobile FDP supporting an offshore wind turbine, there are new and additional sets of design challenges that should be considered and compared with conventional ship-shaped FDP units. The platform should provide enough buoyancy to support the weight and volume needed for the desalination process and to restrain the 
whole system's motions within acceptable operational limits. Moreover, the whole system design should be adjusted to the site for which it is designed.

In the present study, a novel FDP concept powered by a wind turbine was proposed and its platform was selected based on a hydrodynamics numerical study. The novelty aspects of this study are summarised as follows. A new floating desalination platform system is proposed, which is an alternative to the conventional land-based systems, especially for remote coastal areas. The desalination system is fully powered by only renewable energy resources, including wind and solar energy, and was adapted with marine design aspects. Moreover, the floating desalination platform system was mainly designed by considering the environmental conditions in Egypt, which is a developing country suffering from water shortage. The developed floating platform also has specific novel aspects. Instead of considering conventional ship-shaped system, a new unconventional platform was selected since the ship-shaped platform is not suitable to install a large wind turbine due to motion and stability issues. In addition, a specialised software called Water Application Value Engine (WAVE) was used to design a desalination system, which then provided the static weight of the desalination system. This projected weight was taken into account for motion and stability analyses to satisfy the necessary operational criteria for offshore marine structures. Finally, the developed design and procedure could be utilised for similar kinds of platforms used in Egypt.

\section{Problem Description and Selection Criteria}

The conventional FDP powered by fossil fuel had been used before in different commercial projects. For a long time, barge or ship desalination configurations were satisfactory for the conventional FDP concept. The new proposed FDP concept, which supports an offshore wind turbine, faces a unique set of design challenges arising from the combined static loads and the aerodynamic and hydrodynamic loads that have never before been faced by a conventional FDP configuration. In addition to the desalination process, which needs a large volume and has a heavy weight due to the Reverse Osmosis (RO) unit's weights and their water storage tanks, the offshore wind turbine needs a large water plan area to support the dynamic moment loads without affecting the motion responses among the waves. Moreover, the whole system design should be suited to the site for which it is designed. Therefore, the conventional ship-shaped configuration may not be the best choice for an FDP powered by an offshore wind turbine. The objective of this study is to numerically evaluate the different possible configuration alternatives to select the most suitable one for a particular location in Egypt. The platform's static and dynamic responses are analysed based on the following selected criteria:

- Dynamic Stability: Installing a wind turbine on an FDP platform has additional requirements due to the turbine thrust loads. The platform's dynamic responses may lead to a change in the turbine tower's displacement angle. To avoid any negative effect on the turbine's performance, the declining angle should not exceed 6 degrees [18].

- Static Stability: The FDP platform must have sufficient stability to keep itself upright. Stability requirements for floating offshore platforms supporting wind turbines are stated in the design standard DNV-OS-J103 [19]. The standard states that the floating platform should satisfy the intact stability criteria when the wind turbine is producing the largest rotor thrust. 
- Platform Natural Period: Depending on the deployment location, certain wave and wind periods will have substantial energy. The natural period of the FDP platform should therefore be outside of the energy excitation range of waves and winds to avoid resonance and its consequences.

- Global Frequency of Overall System: FDP platforms supporting offshore wind turbines are dynamically responsive to various types of low frequencies, which are induced by environmental and mechanical loads. The global frequency of the overall floating system (turbine and platform) should lie outside the range of excitation frequencies to avoid system resonance. DNV guidelines recommend that the overall floating system's natural frequency should not come close to the excitation frequencies arising from the imposed environmental loads [20]. The guidelines also define that the system's global frequency should be at least $\pm 10 \%$ away from operating blade passing frequencies $(1 \mathrm{P})$ and $2 \mathrm{P} / 3 \mathrm{P}$ frequencies which are related to 2-bladed and 3-bladed wind turbines.

\section{Location and Environmental Loads for FDP Concept}

The deployment site is a critical factor in determining the environmental loads that affect the platform's operation and lifetime. The FDP site location is affected by different factors and constraints based on many social, economic and topographic sets of data. Egypt has $3000 \mathrm{~km}$ of coastline along the Mediterranean Sea $(1150 \mathrm{~km})$, Gulf of Suez and Aquba $(650 \mathrm{~km})$ and the Red Sea $(1200 \mathrm{~km})$ [15]. Furthermore, the Red Sea area has Egypt's highest wind potential with a mean power density in the range of $300-900 \mathrm{~W} / \mathrm{m}^{2}$ at $50 \mathrm{~m}$ height [16]. Although the Red Sea coastline is rich with renewable resources, it is considered remote from the national grid of water and power.

Based on a previous site selection study [22,35], Ras Ghareb was selected as the site of the proposed FDP concept as shown in Figure 1 . The city lies at a latitude of $28.33^{\circ} \mathrm{N}$, a longitude of $33^{\circ} \mathrm{E}$ and an altitude of $56 \mathrm{~m}$. The average draft in this area is $50 \mathrm{~m}$ at a distance from the coastline of $2 \mathrm{~km}$, which makes it shallow water draft, while in Red Sea it is considered as deep water [17]. Ras Ghareb is one of the Red Sea's largest cities in the Gulf of Suez. According to Red Sea governor data, Ras Ghareb's total population is around 60,000 people. Ras Ghareb was selected based on three major reasons: high water demands for civil and industrial applications, suitable water depth and high wind and solar energy potential. 


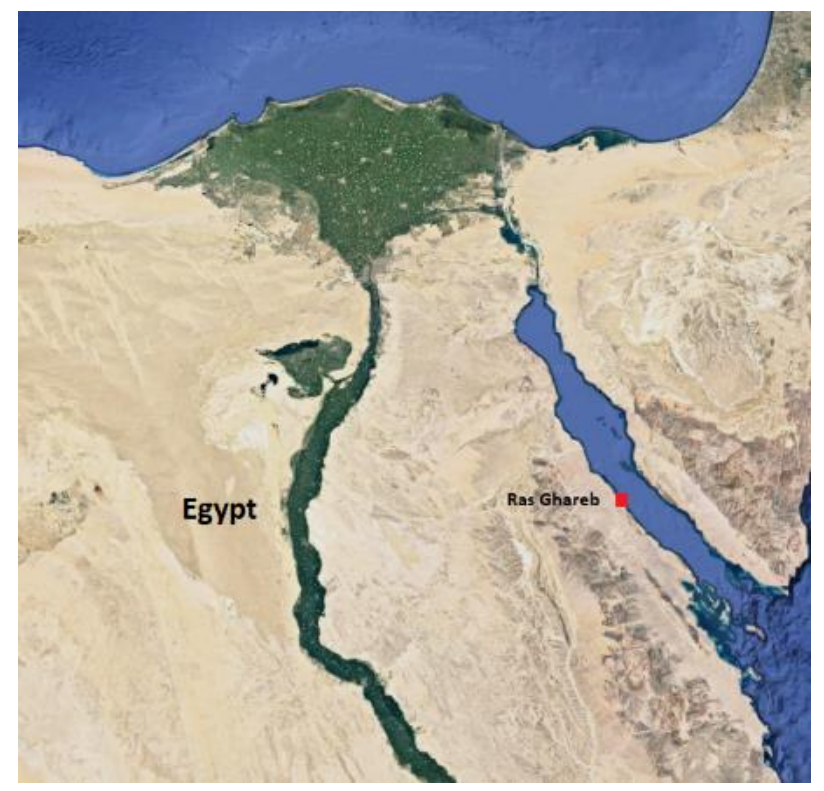

Figure 1: The FDP location at Ras Ghareb.

Wind speed is the first data required for designing the wind turbine for a particular site. Based on the Egyptian Metrological Authority of Ras Ghareb [16 and 17], Ras Ghareb has high wind potential with an average wind speed of $12.5 \mathrm{~m} / \mathrm{sec}$ at 100 -meter height from ground. Monthly average wind speed is plotted in Figure 2. Also, the 50 -year is given at $38 \mathrm{~m} / \mathrm{sec}$.

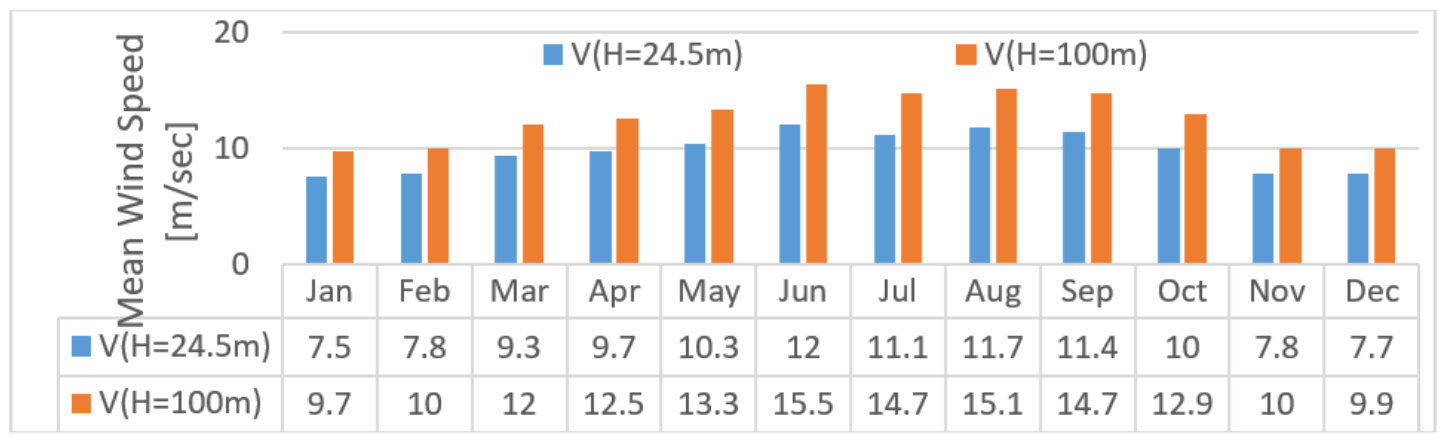

Figure 2: Wind speed at the Ras Ghareb area based on wind measurement station at $24.5 \mathrm{~m}$ and $100 \mathrm{~m}$ [22].

In regards to wave condition, Ras Ghareb area faces rough marine conditions. The significant wave height and wave period were determined for a 1-year return period in the Red Sea zone as $2.15 \mathrm{~m}$ wave height and $5.08 \mathrm{sec}$ wave period [23]. Moreover, maximum wave height and the highest time period occurred for a 1-year return period are $5.18 \mathrm{~m}$ and $6.5 \mathrm{sec}$ and for 100-year return period are $7.92 \mathrm{~m}$ and $8 \mathrm{sec}$ [24 and 25].

Ras Ghareb wave spectrum was estimated according to DNV-GL rule [20] as:

$S_{P M}(\omega)=\frac{\alpha \cdot g^{2}}{\omega^{5}} \cdot \exp \left[-\beta\left(\frac{g}{U \cdot \omega}\right)^{4}\right]$ 
with

$\omega=2 \pi f, \alpha=8.1 * 10^{-3}, \beta=0.74$ and $g=8.1 \mathrm{~m} / \mathrm{sec}^{2}$, and $U$ is the wind speed in $\mathrm{m} / \mathrm{sec}$. The results show that Ras Ghareb's wave band is in the range of 0.5 to $2.0 \mathrm{rad} / \mathrm{sec}$ in this area (see Figure 3). The natural frequency of the proposed FDP concept should be outside of the wave band range to avoid resonance response.

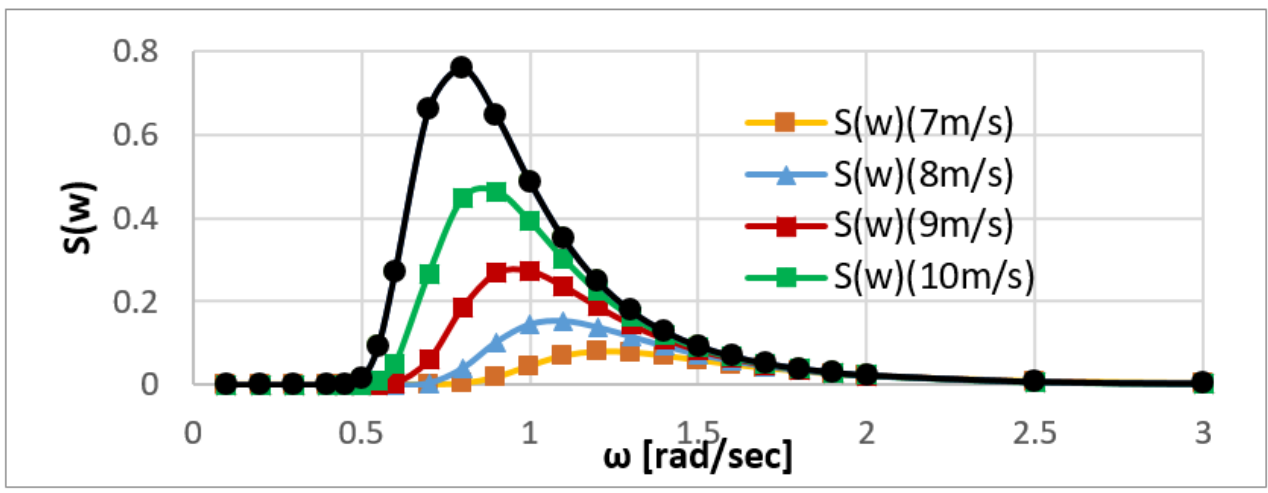

Figure 3: The wave spectrum of the selected location based on wind speed.

\section{Proposed FDP concept}

\subsection{Overview of the desalination system}

In general, the present new FDP concept is a marine vessel equipped with a desalination plant and its power supply system. The RO desalination technology was selected for the proposed FDP concept. The total desalination capacity is $10,000 \mathrm{~m}^{3} /$ day, distributed over six RO modules; each has $2,000 \mathrm{~m}^{3} /$ day capacity with an extra backup module. The proposed desalination system's operation can be summarized in five main steps:

1. Intake the seawater through a feed pump via marine sea chests. Then, the seawater passes through screen filters for preservation in a raw water tank. The raw water tank has been designed to hold up to $6000 \mathrm{~m}^{3}$ of water to continuously feed all desalination units.

2. To pre-treat the seawater, the water is pumped through a dual-media filter to remove the forming microflocs.

3. A brine diffuser then discharged the effluent into the sea.

4. By using high pressure pumps, RO desalination is processed through pressurised water through RO skids. Each RO unit contains 26 vessels that each have 6 membrane modules of the FILMTEC SW30HRLE-440 type.

5. The desalted water is transferred to freshwater storage tanks, then to a shore storage facility.

The proposed desalination system scheme was designed and presented in Figure 4. 


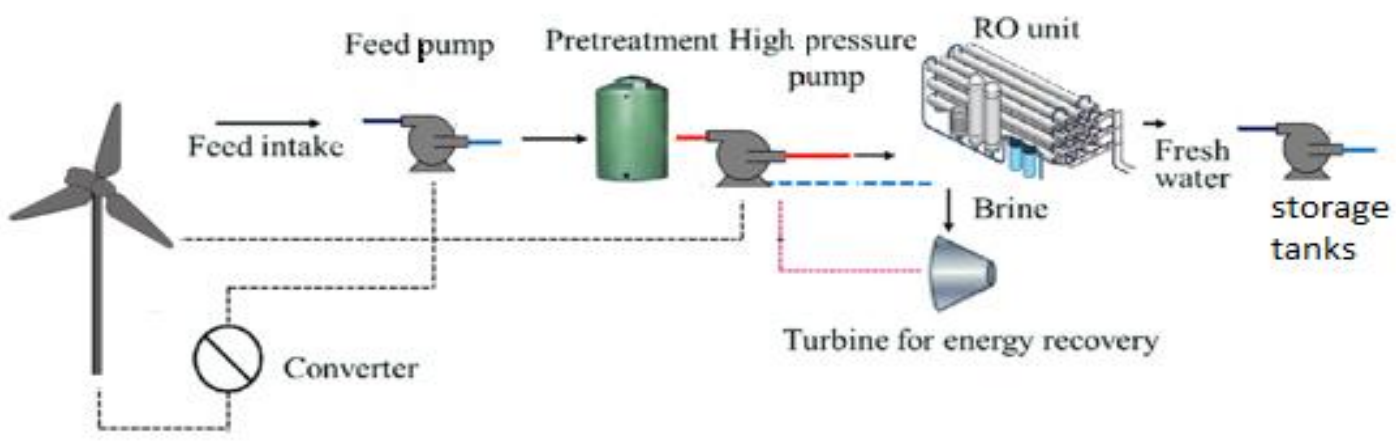

Figure 4: Scheme of the reverse osmosis.

Water Application Value Engine (WAVE) software, version 12.5, was used to design and simulate the RO desalination plant. The row water specifications in Ras Ghareb area were applied as input data into the WAVE program beside the constrains related to the quality of freshwater needed. Through the design and simulation process, the program estimated the output freshwater specifications parameters, the RO unit parameters, the area needed to place the RO modules and the power needed to drive the process. The software simulation results showed that the total active area required for the desalination plant is estimated as $5574 \mathrm{~m}^{2}$. The total weight of desalination unit during the operation is 133 tons for each module [26]. As mentioned earlier, the proposed desalination system was designed to operate with six RO desalination modules, each having a capacity of $2,000 \mathrm{~m}^{3} /$ day and equipped with six freshwater storage tanks with a total capacity of $60,000 \mathrm{~m}^{2}$. The total daily desalinated water is $10,000 \mathrm{~m}^{2}$ and the maximum capacity, if the sixth backup unit is employed, is $12,000 \mathrm{~m}^{2}$. The energy needed to run the plant is estimated at 3 $\mathrm{kW} / \mathrm{h} / \mathrm{m}^{3}$ (3 MW for total capacity) and completely covered by an offshore wind turbine.

\subsection{Wind turbine}

Vestas offshore wind turbine V112-3MW was selected to supply power for the desalination plant. The three-blade turbine has a rotor diameter of 112 meters and a swept area of $9852 \mathrm{~m}^{2}$. The nominal output power is $3 \mathrm{MWh}$ at a rating wind speed of $12 \mathrm{~m} / \mathrm{sec}$. The total turbine weight is 410 tons including the nacelle, blades and tower weights.

The wind load performing on the wind turbine is an aerodynamic load that relies on several parameters such as wind speed or the structure's aerodynamic shape. Particular consideration should be paid to the thrust force and moment produced at the top of the turbine. The thrust derived from the wind turbine can be calculated as:

Thrust $=\frac{1}{2} C_{t} \rho A U^{2}$

where $\rho$ is the air density $\left(1.225 \mathrm{~kg} / \mathrm{m}^{3}\right), A$ is the turbine swept area and $U$ is the wind velocity. $\mathrm{C}_{\mathrm{t}}$ is the thrust coefficient and was obtained for V112-3MW turbine from Vestas Company (the turbine manufacturer) as shown in Figure 5. 
Based on the above equations and the data obtained from the turbine manufacturer, the thrust forces were calculated and plotted in Figure 5. Maximum thrust force occurred at the wind speed of 10 $\mathrm{m} / \mathrm{sec}$ at $400 \mathrm{kN}$.
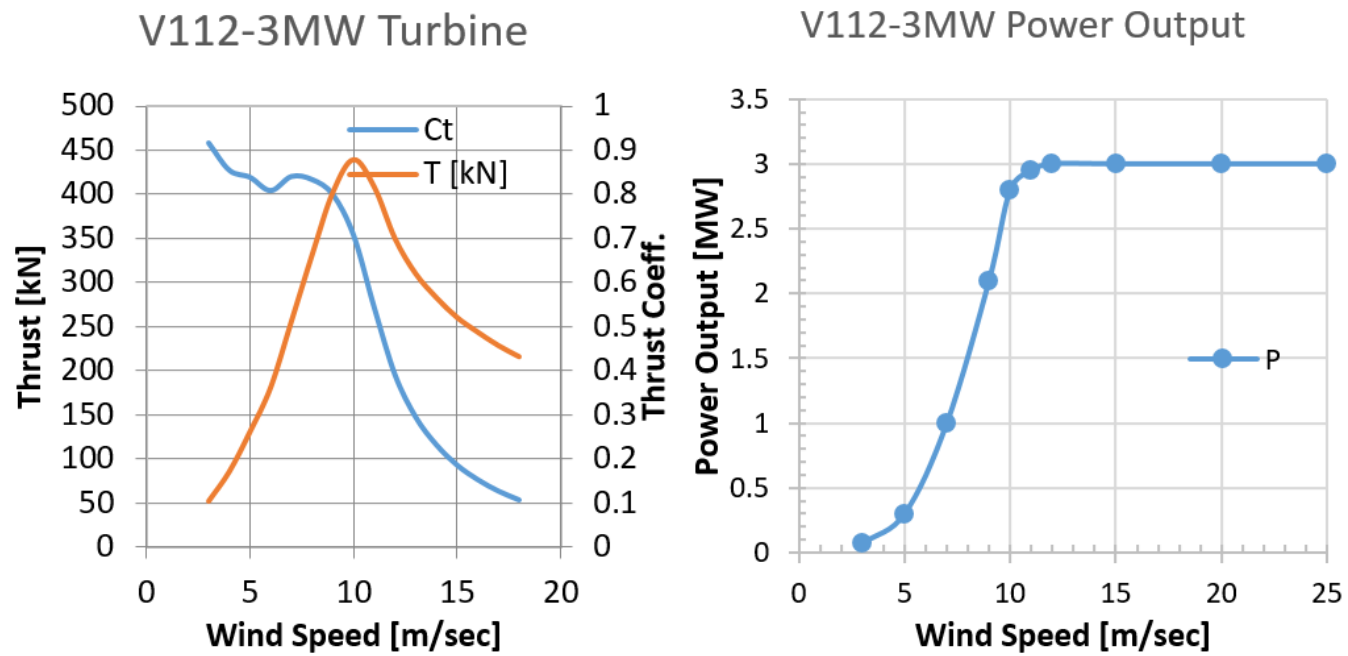

Figure 5: Thrust force, thrust coefficient and power output for various wind speeds of the Vestas V112-3MW turbine.

\subsection{System weight}

The overall system weight is a critical parameter in selecting the suitable platform. According to the information provided by the wind turbines manufacturer, the total weight of the turbine (nacelles, rotors and hubs) was estimated at 410 tons. The total RO units' weight during operation as obtained from the WAVE simulation results was at 133 tons for each unit. To determine the overall platform size and volume, the overall hull steel weight, auxiliary and equipment and the storage and power system weight were preliminary calculated using GeniE DNV-GL Sesam software (see Table 1). The total weight of the whole unit is estimated to be 88,375 tons.

Table 1: Weight components of the FDP concept.

\begin{tabular}{|c|c|}
\hline Items & Weight [ton] \\
\hline Turbine nacelle & 150 \\
\hline Turbine Blades and hub & 70 \\
\hline Turbine tower & 190 \\
\hline RO-unites total weight during operation & 798 \\
\hline Product water storage capacity & 60,000 \\
\hline Feeding tank capacity & 6000 \\
\hline Assumed structure weight and outfitting & 21300 \\
\hline
\end{tabular}

\section{Selection of the FDP platform}


Many of the design principles applied to floating platform hydrodynamics come from the offshore oil and gas industry [6]. However, supporting a wind turbine introduces significant new loads to the floating platform. A hydrodynamic-based design concept helps to determine a suitable platform configuration, which satisfies the dynamic and static constrains and criteria.

\subsection{Investigated platform configurations}

Floating platforms were classified as spar, barge, tension leg platform (TLP), or semi-submersible [27]. In regards to the barge class, there have been different research studies that look at how the barge configuration platform supports wind turbines [28]. In general, the barge platform stabilizing concept relies on a large water plane area to raise the platform's metacentre above its centre of gravity. Heave plates and moonpools design techniques may be used to increase damping and reduce dynamic motions. For example, an open barge-shaped platform based on a central opening moonpool system was installed in the French Atlantic coast in 2018 for Floatgen project to support a 2 MW wind turbine for the French company, IDEOL [32]. Also, the cylindrical barge (FPSO) with and without the heave plate was used as an offshore facility in the oil and gas industry in the Gulf of Mexico. This platform has been deployed as a unique design concept for economic oil production since it has storage capabilities and a wider deck that gives it a better layout in terms of flexibility.

The spar platform is a mono-hull ballast stabilized class. The spar design relies on a deep draft and heavy ballast to make the platform's centre of gravity lie below its centre of buoyancy. A spar floater was tested for offshore wind turbines outside of Karmøy, Norway, in 2009 [29]. The successful test resulted in the installation of five $6 \mathrm{MW}$ turbines located at Buchan Deep outside of Scotland in October 2017. Various configurations of the semi-submersibles class are used as a wind turbine floater. The Fukushima V-shaped semi-submersible and sea angle platform have been used [30]. Another configuration with a triangular pontoon has been chosen for further studies. The pontoons are joined together in a closed triangle and have the same width as the diameter of the columns. An example of a semi-submersible support structure design is the WindFloat, which was tested in 2011 with a 2 MW turbine operating outside of Portugal [31].

Since the design principals of any offshore platform configuration affects the motion characteristics and operability, and based on the above mentioned platforms, the dynamic and static performance will be evaluated numerically (in section 6) for different common platform configurations to select the suitable platform shape for the new FDP supporting a wind turbine. The main focus of this study is to make a realistic selection for operation in Egyptian environmental conditions. It's important to note that the proposed FDP concept has a dual function: supporting a heavy displacement load from the desalination plant and supporting a wind turbine, which needs stability in operation. In addition, the platform has a mobility function; therefore, the tension leg platform was excluded from this study due to its complex and stationary mooring system. The platform displacement parameter is the main fixed parameter to compare different platform configurations. The selected platform parameters in this study are summarized in Table 2. 
Table 2: The platforms selected in the present study.

\begin{tabular}{|c|c|c|c|c|c|c|}
\hline Platform type & Disp. & Draft & $\begin{array}{l}\text { Width / } \\
\text { diameter }\end{array}$ & Length & height & Shape \\
\hline a- Cube platform & & $22.4 \mathrm{~m}$ & $62.04 \mathrm{~m}$ & $62.04 \mathrm{~m}$ & $32 \mathrm{~m}$ & 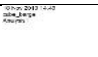 \\
\hline $\begin{array}{l}\text { b- Cylindrical } \\
\text { platform }\end{array}$ & & $22.4 \mathrm{~m}$ & $70 \mathrm{~m}$ & & $32 \mathrm{~m}$ & $z$ \\
\hline $\begin{array}{l}\text { c- Cylinder with } \\
\text { heave plate }\end{array}$ & & $21 \mathrm{~m}$ & $70 \mathrm{~m}$ & & $32 \mathrm{~m}$ & $=$ \\
\hline $\begin{array}{l}\text { d- Hexagonal } \\
\text { platform }\end{array}$ & 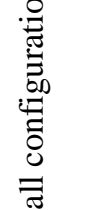 & $22.4 \mathrm{~m}$ & $64 \mathrm{~m}$ & $80.2 \mathrm{~m}$ & $32 \mathrm{~m}$ & $=$ \\
\hline $\begin{array}{l}\text { e- Cuboids } \\
\text { platform }\end{array}$ & 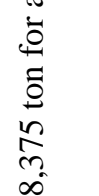 & $14.91 \mathrm{~m}$ & $36 \mathrm{~m}$ & $170 \mathrm{~m}$ & $32 \mathrm{~m}$ & $=$ \\
\hline f- Semisubmersible & 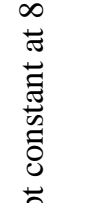 & $22.4 \mathrm{~m}$ & $80 \mathrm{~m}$ & $100 \mathrm{~m}$ & $32 \mathrm{~m}$ & L \\
\hline $\begin{array}{l}\text { h- Sea angle (V } \\
\text { semisubmersible) }\end{array}$ & $\begin{array}{l}\overrightarrow{\vec{a}} \\
\overrightarrow{0} \\
\overrightarrow{0} \\
\overrightarrow{0} \\
\overrightarrow{0} \\
\overrightarrow{0}\end{array}$ & $20 \mathrm{~m}$ & $100 \mathrm{~m}$ & $100 \mathrm{~m}$ & $32 \mathrm{~m}$ & 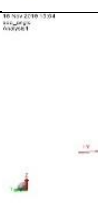 \\
\hline i- Open barge & $\ddot{a}$ & $22.4 \mathrm{~m}$ & $80 \mathrm{~m}$ & $80 \mathrm{~m}$ & $32 \mathrm{~m}$ & $=2$ \\
\hline $\begin{array}{l}\text { j-Triangle } \\
\text { semisubmersible }\end{array}$ & & $32 \mathrm{~m}$ & $68.45 \mathrm{~m}$ & $68.45 \mathrm{~m}$ & $40 \mathrm{~m}$ & \\
\hline k- Spar & & $94.96 \mathrm{~m}$ & $34 \mathrm{~m}$ & & $100 \mathrm{~m}$ & $=$ \\
\hline
\end{tabular}




\subsection{Environmental and wind turbine mechanical loads}

Dynamic loads acting on floating platform that support the wind turbine can be measured from four sources: wind load, wave crushing, aerodynamic asymmetry of the rotor (1P) and bladeshadowing effect (3P) [18]. The design zone alternatives for the floating platform supporting a wind turbine can be outlined in three different design options: soft-soft, soft-stiff and stiff-stiff. The soft-soft design option requires a flexible structure with its first natural frequency being smaller than the rotor frequency range (1P), which is achievable only with the floating systems. Moreover, the platform structures can be designed with the stiff-stiff design principle with a greater natural frequency than the range of the blade-shadowing effect frequency (3P). Therefore, the stiffstiff design alternative is not feasible to construct for this project due to its high-cost need of a massive foundation. Apart from those two options, the soft-stiff is the most common design practice in fixed offshore wind turbines, which limits the structure's natural frequency between the $1 \mathrm{P}$ and $3 \mathrm{P}$ range.

The typical frequency spectra of dynamic loads determined for Egypt are shown in Figure 6. The rotor frequency (1P) lies in the range of $0.79-2.18 \mathrm{rad} / \mathrm{sec}$ and the blade passing frequency for a three-bladed turbine lies in the range of 2.28-3.77 $\mathrm{rad} / \mathrm{sec}$. The figure also shows the frequency excitation loads' distributions from wind and wave in the deployment area. The peak wave load frequency of the Ras Ghareb area is about $0.8 \mathrm{rad} / \mathrm{sec}$. Note that to avoid system resonance, the selected platform's global natural frequency must be lie outside the range of forcing frequencies that arise from the imposed environmental loads. DNV-GL Guidelines (2002) suggest that the system's global frequency should be at least $\pm 10 \%$ away from the operational $1 \mathrm{P}$ and $2 \mathrm{P} / 3 \mathrm{P}$ frequencies, as indicated by the dotted lines in Figure 6.

Taking into account the constraints described above, the wind and wave spectra of the Ras Ghareb zone and operational speeds of V112-3.3MW wind turbine provided by the manufacturer (Vestas Wind Systems A/S. 2013), the proposed optimum design range is selected to be far from those excitation frequencies and satisfy the dynamic motion criteria in section 2 . The optimum design zone is indicated by orange lines in the power spectral density diagram in Figure 6.

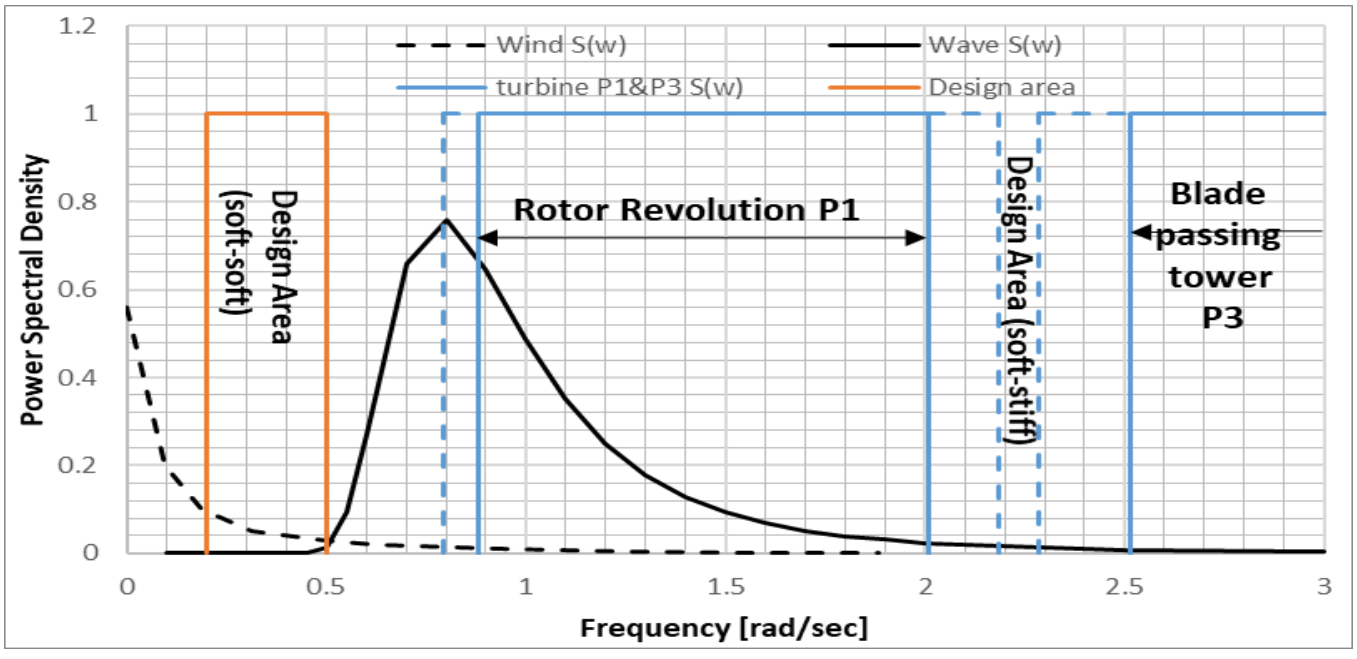

Figure 6: Frequencies of external loads and the structure of the wind turbine. 


\section{Methodology}

\subsection{Numerical Methodology}

The primary numerical tool used in this study was the Sesam software package for offshore platform design and simulation. This software was developed by DNV-GL. GeniE module was the primary software where the platforms hulls were modelled, as shown in Table 3. HydroD, one of the Sesam package solvers, can perform stability, frequency domain and time domain simulations. In this study, HydroD software was used to calculate the platform's response and static stability performance. The output of this process was the response amplitude operator (RAO) and static stability parameters.

The platform models were generated using GeniE modeller V7.4-18 software using 3D diffraction panels that represent the outer geometry of the platform structures. The platform's wetted surface was discretised into panel sizes of $0.1 \mathrm{~m}$. The frequency domain analysis was performed using HydroD V4.9-02. Linear hydrodynamics analysis wizard "Wadam" was selected in this study. Due

to the large model bodies, the panel method was selected to calculate hydrostatic and hydrodynamic forces based on potential theory. The software program setting was adapted on frequency domain analysis. Element model was selected without roll damping, load cross sections and load transfer.

Due to the symmetrical shape of the model (cylinder platform), one wave direction at zero angle was set. Frequency range was set from 0 to $1.5 \mathrm{rad} / \mathrm{sec}$ and frequency step was set at $0.01 \mathrm{rad} / \mathrm{sec}$. Hydrodynamic model, load condition and environmental condition were applied to be matching with the environmental condition in Ras Ghareeb in Egypt. All model concepts were simulated at $300 \mathrm{~m}$ water depth in free floating conditions without mooring arrangement in order to focus on configuration parameter only in this study.

\subsection{Methodology Validation}

To identify the numerical tool's validity, the analytical model was used to predict the motion response of a floating cylinder platform based on the dynamic linear model of the spar-buoy as developed and validated by Seif et al. [33].

The motion performance of a floating cylinder is modelled numerically by Sesam HydroD. The heave RAO, heave force, damping force and added mass associated with the periodic motions are compared with the analytical model. The cylinder has a diameter of 70 meter and $22 \mathrm{~m}$ draft and is floating in deep water (same parameters as the cylindrical platform in Table 3 ).

As shown in Figure 7 (c), the numerical results obtained by using Sesam software agree with the results from the analytical method. Thus, we can conclude that the HydroD numerical solver can be used for the analysis of other platforms considered in this study. 


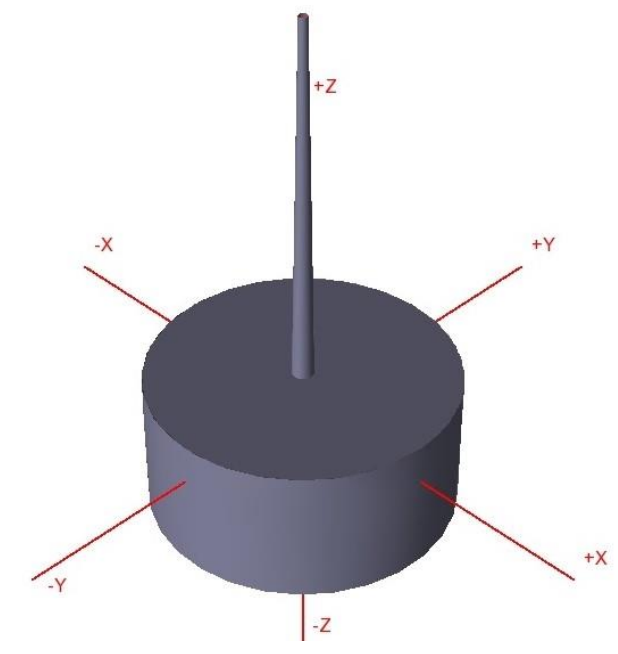

(a)

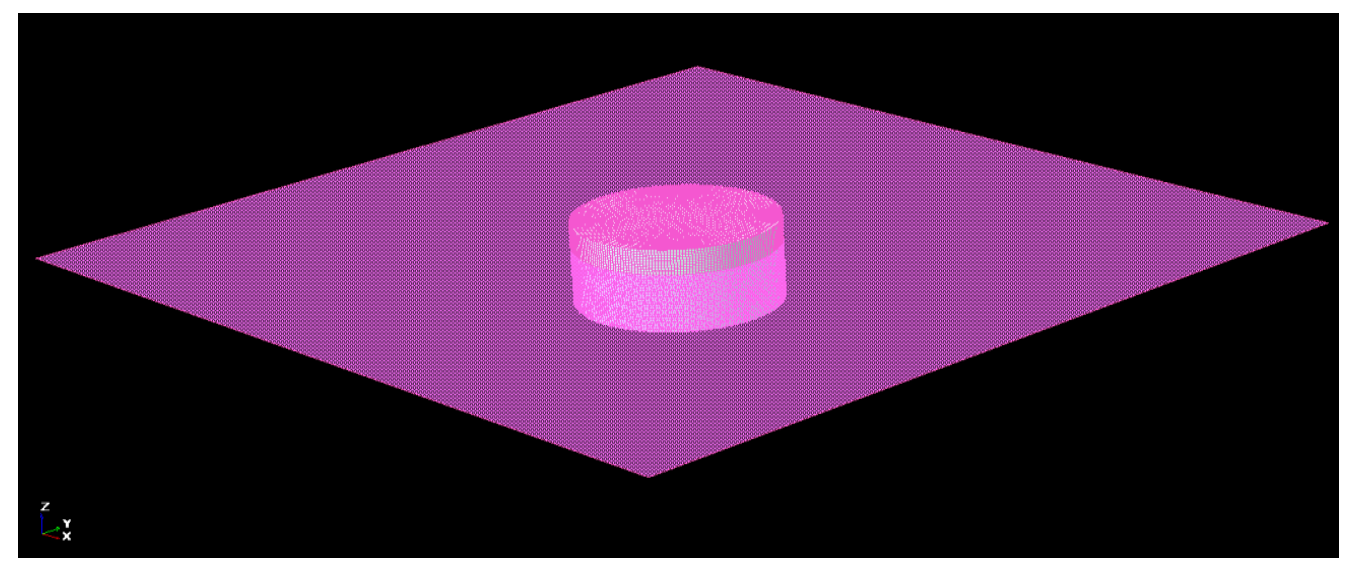

(b) 

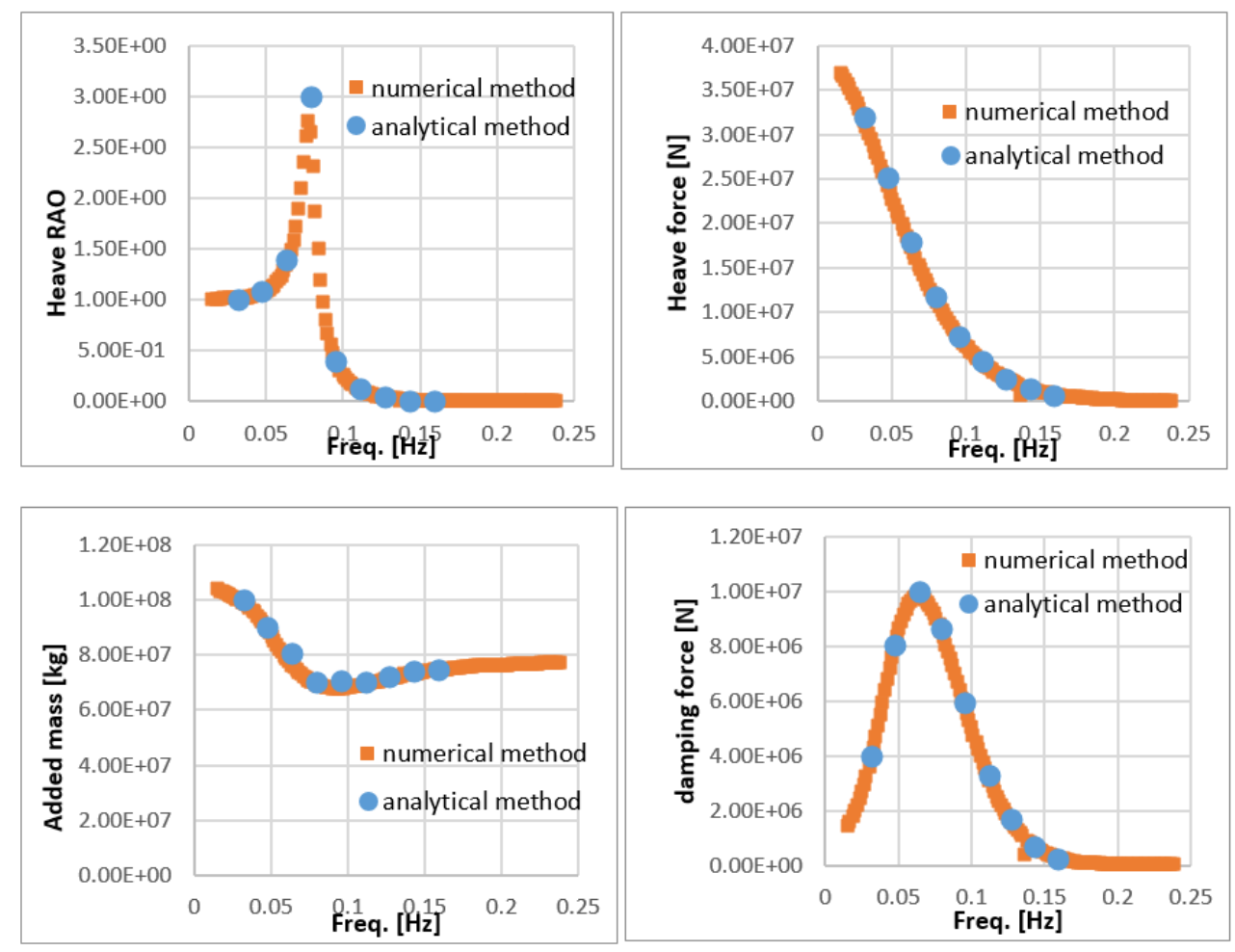

(c)

Figure 7. (a) the platform, (b) meshing, (c) heave RAO, force, added mass and damping results.

\section{Results and Discussion}

In this section, the motion responses and stability analysis were investigated. The platform total mass parameter, as estimated in section 4.3, was kept constant to investigate the effect of the platform shape on the stability and motion performance. The assessment of the first natural frequency of the offshore platform supporting the wind turbine is an important part of the structural analysis. Therefore, the compatibility of platform natural frequency with Egyptian environmental loads and the mechanical loads induced by the selected wind turbine were evaluated based on the selected optimum design area as determined in section 5.2 (Figure 6).

\subsection{Results of dynamic responses}

HydroD software was used to evaluate the dynamic response for different platforms selected in the previous section. Heave RAO motion is presented in Figure 8. The structure's global natural frequency should be outside of the high energy excitation range of the wind, waves and wind turbine operation frequencies. The orange box presents the suitable soft-soft safe design zone $(0.2$ to $0.5 \mathrm{rad} / \mathrm{sec}$ ) where the global frequency of the selected platform will be out of the energy excitations. According to the heave RAO's results, only spar, semi-submersible and cylinder barge with heave plate are inside this range, while all other platforms are outside the design range. The spar platform has the largest heave response and the semi-submersible platform experiences smallest motions. 


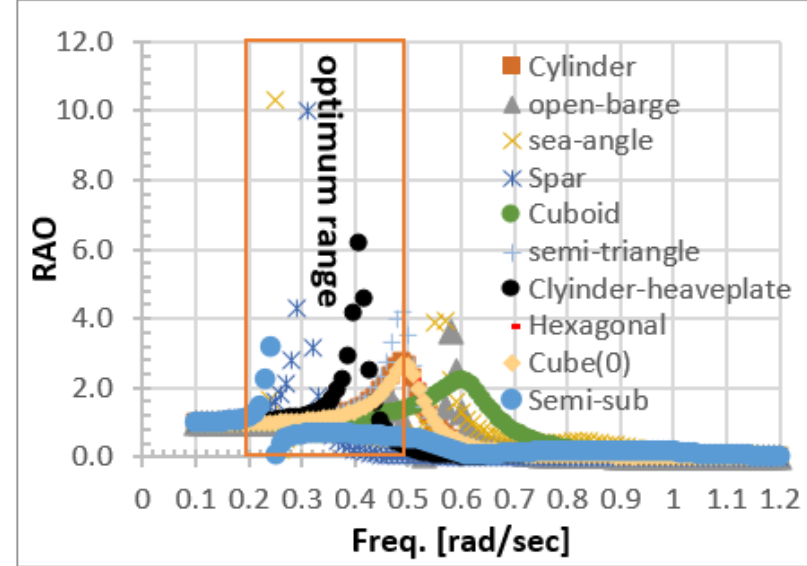

Figure 8: Heave dynamic responses.

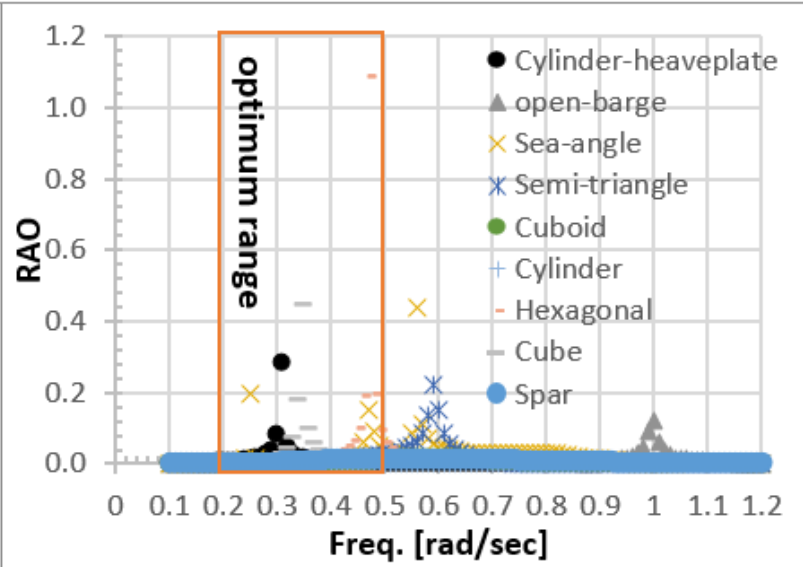

Figure 9: Pitch dynamic responses.

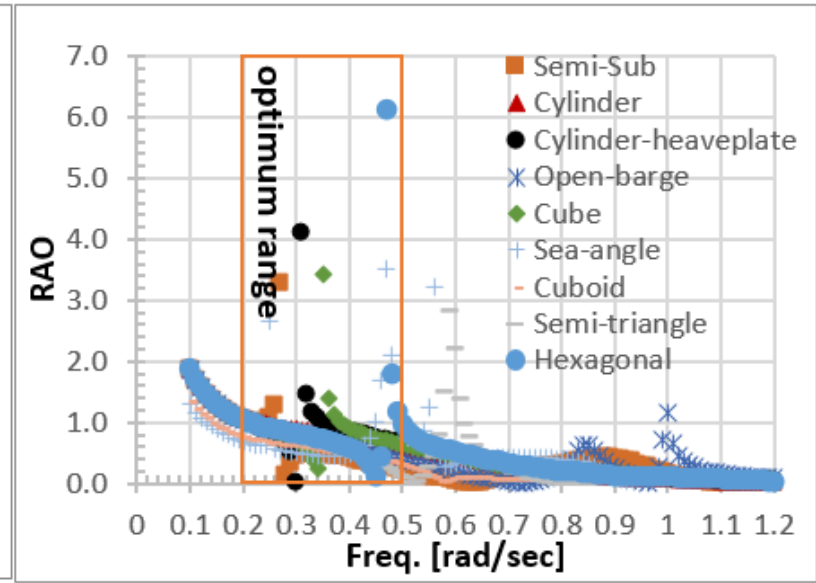

Figure 11: Surge dynamic responses.

Figure 10: Roll dynamic responses.

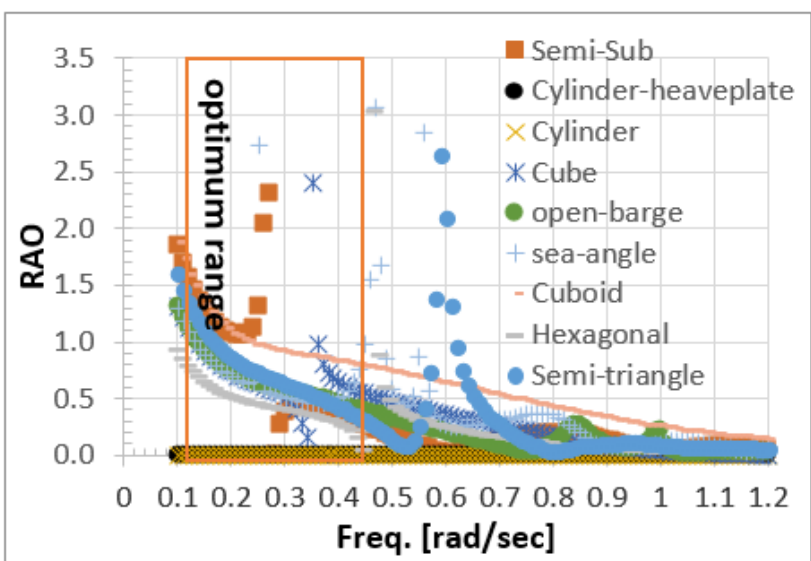

Figure 12: Sway dynamic responses.

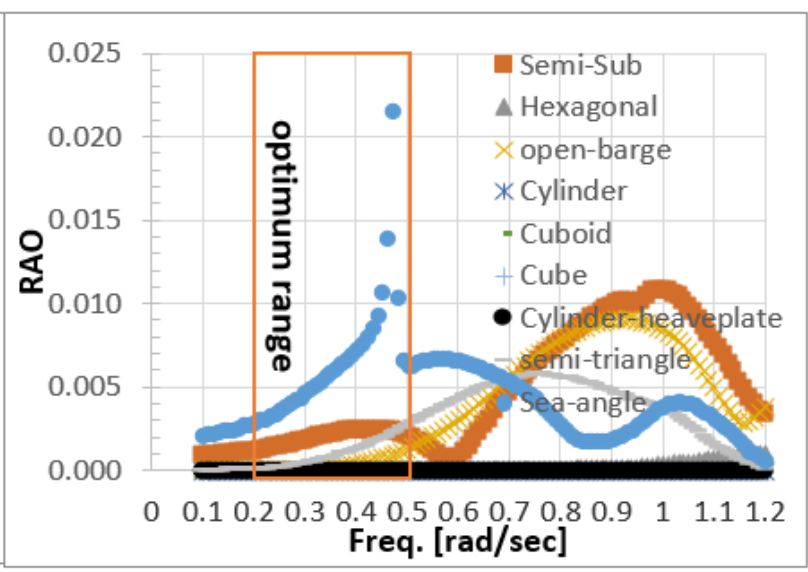

Figure 13: Yaw dynamic responses.

From Figure 9, the following conclusions can be made. The cylinder platform with heave plate, spar, cube and hexagonal platforms experience suitable responses within the optimum design soft- 
soft range (as determined in section 5.2), with respect to other platforms. The cube platform has the largest pitch response and the spar experiences smallest motions.

Figure 10 shows that the semi-submersible experiences large roll responses, while the cylinder hull with heave plate and spar have smallest roll responses. Spar, cylinder and cylinder with heave plate platforms have xz and yz symmetry and their restoring capabilities are equal in both roll and pitch as well as drag in both surge and sway.

According to the surge motion results in Figure 11, the semi-submersible, cube, hexagonal, cuboids, cylinder and cylinder with heave plate platforms have experienced suitable responses within soft-soft design range, rather than the triangle semi-submersible, open barge and sea angle platforms. The hexagonal platform has the largest surge response, while the cuboids platform has the smallest. The results for sway motion in Figure 12 show that the semi-submersible, cube, hexagonal, cuboids, cylinder and cylinder with heave plate platforms have experienced suitable responses within soft-soft design range, rather than triangle semi-submersible, open barge and sea angle platforms. The hexagonal platform has the largest surge response, while the cuboids platform has the smallest response.

According to the yaw motion results in Figure 13, the cuboids, cylinder, cube, hexagonal and cylinder with heave plate platforms have experienced suitable responses within soft-soft design range, rather than the triangle semi-submersible, open barge, semi-submersible and sea angle platforms. The sea angle platform has the largest surge response, while the cuboids, cylinder and cylinder with heave plate platforms have the smallest responses.

\subsection{Results of static stability}

The structure must have sufficient stability to keep itself upright, which is defined as having a stable equilibrium. The structure also must be capable of handling a disturbance, such as exciting forces or moments, and can return back to equilibrium after the excitation has ended. Stability requirements for floating offshore wind turbines are stated in the design standard DNV-GL [20]. This states that the floating structure must be capable of maintaining the wind turbine's stability at the wind speed that is producing the largest rotor thrust. It must also be capable of maintaining stability with the rotor at a standstill in severe storm conditions. Wayman [34] states that the turbine efficiency will be substantially reduced for pitch angles greater than 6 degrees. To maintain turbine efficiency, the static pitch angle is limited to 6 degrees in this study. Only the spar and semi-submersible platforms exceed 6 degrees when the normal operation of the turbine thrust force is applied, while all other platforms are within the safe limit of turbine operation, as shown in Figure 14. The higher righting arm (GZ) is expressed by tri-semisubmersible platform, while the lower GZ is for the cylinder hull without heave plate.

Static stability results from HydroD module are presented in Table (3). Based on the general requirement of the International Maritime Organization (IMO), the minimum operational metacentric height (GM) should be larger than $1 \mathrm{~m}$. The maximum righting lever (GZ) must occur at an angle of heel not less than $25^{\circ}$. The area under the righting lever curve (GZ curve) must not be less than 0.055 metre-radians up to an angle of heel $40^{\circ}$. According to the static stability results, all platforms satisfied the IMO criteria. The open-barge platform performed the best GM value, 
while the cuboid performed the less value. Maximum GZ happened for the spar platform, while the less GZ was produced by cylinder platform.

Table 3: Static stability summary

\begin{tabular}{|c|c|c|c|c|c|}
\hline Platform type & GM & $\mathrm{GZ}_{\max }$ & $\begin{array}{l}\text { Angle of max } \\
\text { GZ [deg] }\end{array}$ & $\begin{array}{l}\text { End of stability } \\
\text { range }\end{array}$ & $\begin{array}{l}\text { Area under GZ } \\
\text { curve up to } 40^{\circ}\end{array}$ \\
\hline Cube & $9.5 \mathrm{~m}$ & $4.54 \mathrm{~m}$ & 39 & 90 & 2.07 \\
\hline Semi-triangle & $24.23 \mathrm{~m}$ & $15.56 \mathrm{~m}$ & 40 & 101 & 6.80 \\
\hline Sea angle & $17.74 \mathrm{~m}$ & $10.14 \mathrm{~m}$ & 46 & 122.5 & 4.48 \\
\hline Semi-sub & $5.95 \mathrm{~m}$ & $11.59 \mathrm{~m}$ & 39 & 105 & 4.80 \\
\hline Hexagonal & $9.53 \mathrm{~m}$ & $4.55 \mathrm{~m}$ & 40 & 90 & 2.05 \\
\hline Open-barge & $30.3 \mathrm{~m}$ & $10.22 \mathrm{~m}$ & 32 & 98.28 & 5.33 \\
\hline Spar & $5.28 \mathrm{~m}$ & $18.7 \mathrm{~m}$ & 108 & 180 & 1.41 \\
\hline Cuboid & $3.723 \mathrm{~m}$ & $7.0 \mathrm{~m}$ & 78 & 180 & 1.07 \\
\hline Cylinder & $8.87 \mathrm{~m}$ & $4.32 \mathrm{~m}$ & 40 & 89.99 & 1.93 \\
\hline Cylinder with heave plate & $10.58 \mathrm{~m}$ & $8.9 \mathrm{~m}$ & 40 & 109.2 & 3.12 \\
\hline
\end{tabular}

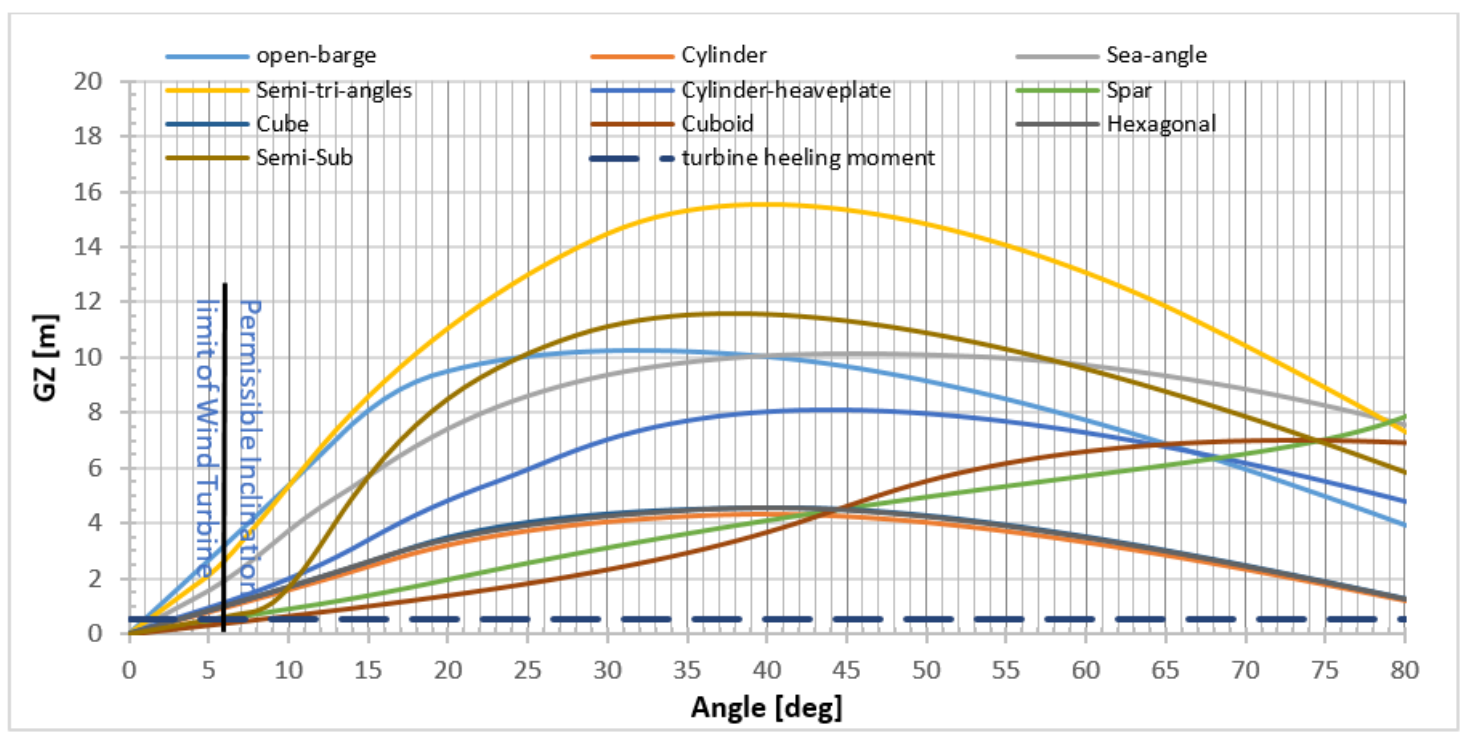

Figure 25: Static stability analysis. 
Table 4: Summary of different configuration hydrodynamics performance

\begin{tabular}{|c|c|c|c|c|c|c|c|}
\hline Configuration & Heave & Pitch & Roll & Surge & Sway & Yaw & $\begin{array}{c}\text { Static } \\
\text { Stability }\end{array}$ \\
\hline Cube platform & Critical & $\sqrt{ }$ & $\sqrt{ }$ & $\sqrt{ }$ & $\sqrt{ }$ & $\sqrt{ }$ & $\sqrt{ }$ \\
\hline Cylinder platform & Critical & $\sqrt{ }$ & $\sqrt{ }$ & $\sqrt{ }$ & $\sqrt{ }$ & $\sqrt{ }$ & $\sqrt{ }$ \\
\hline $\begin{array}{l}\text { Cylinder with heave } \\
\text { plate }\end{array}$ & $\sqrt{ }$ & $\sqrt{ }$ & $\sqrt{ }$ & $\sqrt{ }$ & $\sqrt{ }$ & $\sqrt{ }$ & $\sqrt{ }$ \\
\hline Hexagonal platform & Critical & Critical & $\sqrt{ }$ & Critical & $\sqrt{ }$ & $\sqrt{ }$ & $\sqrt{ }$ \\
\hline Cuboids platform & $\mathrm{X}$ & $\sqrt{ }$ & $\sqrt{ }$ & $\sqrt{ }$ & $\sqrt{ }$ & $\sqrt{ }$ & $\mathrm{X}$ \\
\hline Semisubmersible & $\sqrt{ }$ & $\sqrt{ }$ & $\sqrt{ }$ & $\sqrt{ }$ & $\sqrt{ }$ & $\mathrm{X}$ & $\mathrm{X}$ \\
\hline $\begin{array}{l}\text { Sea angle } \\
\text { semisubmersible) }\end{array}$ & $\mathrm{X}$ & $\mathrm{X}$ & $\mathrm{X}$ & $\mathrm{X}$ & $\mathrm{X}$ & $\sqrt{ }$ & $\sqrt{ }$ \\
\hline Open barge & $\mathrm{X}$ & $\mathrm{X}$ & $\mathrm{X}$ & $\mathrm{X}$ & $\sqrt{ }$ & $\mathrm{X}$ & $\sqrt{ }$ \\
\hline $\begin{array}{l}\text { Triangle } \\
\text { semisubmersible }\end{array}$ & $\mathrm{X}$ & $\mathrm{X}$ & $\mathrm{X}$ & $\mathrm{X}$ & $\mathrm{X}$ & $\mathrm{X}$ & $\sqrt{ }$ \\
\hline Spar & $\sqrt{ }$ & $\sqrt{ }$ & $\sqrt{ }$ & $\sqrt{ }$ & $\sqrt{ }$ & $\sqrt{ }$ & $\mathrm{X}$ \\
\hline
\end{tabular}

Based on the dynamic and static stability analysis, the different configurations' hydrodynamic performance are summarized in Table 4. By applying the selection criteria as previously discussed, all platform configurations whose telling angle due to wind force exceeds 6 degrees are excluded and marked with a sign $(\mathrm{X})$ including spar, semi-submersible and cuboids platforms, as shown in Table 4. The platforms which had their dynamic response out of the soft-soft design area are also excluded for the selection and marked with the same sign (X). Some platforms had a dynamic response inside the design area, but are very near to the design limit. Those platforms are marked with (critical) including hexagonal cylinder and cube platforms.

\section{Conclusion}

The FDP concept powered by an offshore wind turbine is proposed as an innovative solution for water shortage in Egyptian remote coastal cities. This unit faces a unique set of new design challenges arising from the combined static, aerodynamic and hydrodynamic loads that have never before been faced by a conventional FDP configuration. A novel RO desalination system is specially designed for this concept. The safe design zone is determined taking into account the Egyptian environmental loads and the turbine operation constraints to select the platform far from resonance and its dangerous consequence. The motion responses and hydrodynamic performances are evaluated in this study using the numerical tools of the Sesam package to select the most suitable platform for the new FDP concept. Based on the comparison of the different platform concepts presented in this study, a cylinder hull form with a heave plate platform demonstrated better static and dynamic performance within the soft-soft safe design zone and is outside the range of excitation frequencies of the Ras Ghareb deployment area. While the heave motion response for sea angle, open barge and cuboids platforms coincide with the frequency band of the wind turbine operates (1P) and wave frequency loads in the Ras Ghareb area, the open barge, sea angle and triangle semi-submersible also coincide with the frequency excitation band of the pitch, roll, sway and surge motions. Semi-submersible experience high response out of a safe design range in yaw motion. Hexagonal, cylinder and cube platforms are still within the soft-soft design area but they are not the best choice. Their natural frequencies were close to the frequencies of the cyclic 
dynamic excitation force of wave in the Ras Ghareb area. Moreover, the semi-submersible and spar platforms do not satisfy the stability criteria of the floating platform supporting a wind turbine. When the thrust moment of the turbine is applied, their inclination angles were more than 6 degrees. Further investigation is needed for mooring types, arrangements and restoring forces which may affect the selection of platform configuration.

\section{Acknowledgment}

The authors acknowledge the British Council and Science and Technological Development Fund (STDF) for support the project NO. 30707 (Mobile Reverse Osmosis Floating Desalination Platform Powered by Hybrid Renewable Energy). In addition, the authors acknowledge the University of Strathclyde's Department of Naval Architecture, Ocean and Marine Engineering and Desert Research centre for the technical expertise and support provided during the period of this research.

\section{References}

1-European Environmental Agency (EEA), Water Is Life. 2018.

2-WWAP, The United Nations World Water Development Report 2018: Nature-based Solutions, UNESCO, Paris, 2018.

3-El-Sadek, A., Water desalination: An imperative measure for water security in Egypt. Desalination, Vol. 250, 2010, pp 876-884.

4-Omer, M. and Moussa, A. Water management in Egypt for facing the future challenges. Journal of Advanced Research, 2016, Vol. 7, pp 403-412.

5-Hafez, A. and El-Manharawyb, S. Economics of seawater RO desalination in the Red Sea region, Egypt. Part 1. A case study. Desalination, Vol. 153, 2002, pp 335-347.

6-Atallah, M., Farahat, M., Lotfy, M. and Senjyu, T. Operation of conventional and unconventional energy sources to drive a reverse osmosis desalination plant in Sinai Peninsula, Egypt. Renewable Energy, Vol. 145, 2020, pp 141-152.

7-Chouski, B. AquaTDPB3DP plants and systems: floating modular dismountable desalination equipment. Desalination Journal, Vol 153, 2002, pp 349-354

8-Chouski, B. AquaTDP/S3DP plants and systems. Floating ship-borne modular dismountable seawater desalination plant. Desalination, Vol. 165, 2004, pp 369-375.

9-Fadel, M., Wangnick, K., and Wada, N., FLOATING DESALINATION PLANTS AN ENGINEERING, OPERATING AND ECONOMIC APPRAISAL. Desalination Journal Vol 45, 1983, pp 49-63.

10-Vasjukov, V., Klyikov, D., Podbereznyi, V. and Shipilov, V. Floating nuclear desalination plant AFWS-40. Desalination, Vol. 89, 1992, pp 21-32. 
11-BABU, P. and REDDY, D. EXISTING METHODOLOGIES IN THE DESIGN AND ANALYSIS OF OFFSHORE FLOATING NUCLEAR POWER PLANTS. Nuclear Engineering and Design, Vol. 48, 1978, pp 167-205.

12-Al-Othmana, A., Darwishb, N., Qasima, M., Tawalbehc, M., Darwisha, N. and Hilald, N. Nuclear desalination: A state-of-the-art review. Desalination, Vol. 457, 2019, pp 39-61.

13-Daltona, G., Bardóczb, T., Blanchc, M., Campbelld, D., Johnsone, K., Lawrenceb, G., Lilasf, T., Friis-Madseng, K., Neumannh, F., Nikitasf, N., Ortegai, S., Pletsasj, I., Simali, P., Sørenseng, H., Stefanakouk, A., and Mastersj, I. Feasibility of investment in Blue Growth multiple-use of space and multi-use platform projects; results of a novel assessment approach and case studies. Renewable and Sustainable Energy Reviews, Vol. 107, 2019, pp 338-359.

14-Collu, M., Maggi, A., Gualeni, P., Rizzo, C. and Brennan, F. Stability requirements for floating offshore wind turbine (FOWT) during assembly and temporary phases: Overview and application. Ocean Engineering, Vol. 84, 2014, pp 164-175.

15-Mahdy, M. and Bahaj, A. Multi criteria decision analysis for offshore wind energy potential in Egypt. Renewable Energy, Vol. 118, 2018, pp 278-289.

16-Ahmed, A. Electricity generation from the first wind farm situated at RasGhareb, Egypt. Renewable and Sustainable Energy Reviews, Vol. 16, 2012, pp 1630- 1635.

17-Ahmed, A. Investigation of wind characteristics and wind energy potential at RasGhareb, Egypt. Renewable and Sustainable Energy Reviews, Vol. 15, 2011, pp. 2750-2755.

18-Butterfield, S., Musial, W., Jonkman, J., Sclavounos, P. Engineering Challenges for Floating Offshore Wind Turbines. Copenhagen Offshore Wind Conference, Copenhagen, Denmark, October 26-28, 2005.

19-Musial, W., Butterfield, S. and Boone, A., Feasibility of Floating Platform Systems for Wind Turbines, ASME Wind Energy Symposium, Reno, Nevada, 5-8 January, 2004.

20-Design of Floating Wind Turbine Structures, DVN-GL rule, DNV-OS-J103, JUNE 2013.

21-Mortensen, N., Gylling, S. and Badger, J. Wind Atlas for Egypt. DTU Library, 2006.

22- Islam Amin, Mohamed E.A. Ali, Seif Bayoumi, Selda Oterkus, Hosam Shawky and Erkan Oterkus. Conceptual Design and Numerical Analysis of a Novel Floating Desalination Plant Powered by Marine Renewable Energy for Egypt. Journal of marine science and engineering, Vol. 8, 2020, pp 95. (doi:10.3390/jmse8020095).

23-Reghu, S. and Sruthy, S. A Comparison of Fatigue Life Improvement Methods for an Existing Offshore Jacket Platform Structure. International Journal of Engineering \& Technology, Vol. 7 (4.5), 2018, pp 333-340.

24-Abdel-Raheem, S., Aal, E., Abdel-Shafy, A. and Abdel-Seed, F., Nonlinear Analysis of Offshore Structures under Wave Loadings. 15th World Conference on Earthquake Engineering 2012 (15WCEE), 24-28 September 2012, Lisbon, Portugal. 
25-Khalifa, A., Haggag, S. and Fayed, M. Fatigue Assessment Analysis of Offshore Structures with Application to an Existing Platform in Suez Gulf, Egypt. World Applied Sciences Journal 30 (8): 1000-1019, 2014, (ISSN 1818-4952).

26- Islam Amin, Saishuai Dai, SeldaOterkus, Sandy Day and Erkan Oterkus. Experimental investigation on the motion response of a novel floating desalination plant for Egypt. Ocean Engineering, Volume 210, 15 August 2020, 107535.

27-Pham, T. and Shin, H. A New Conceptual Design and Dynamic Analysis of a Spar-Type Offshore Wind Turbine Combined with a Moonpool. Energies, 2019, Vol. 12, (3737; doi:10.3390/en12193737).

28-Bagbanci, H. DYNAMIC ANALYSIS OF OFFSHORE FLOATING WIND TURBINES. (https://fenix.tecnico.ulisboa.pt/downloadFile/395143515896/dissertacao.pdf)

29-Driscoll, F., Jonkmana, J., Robertsona, A., Sirnivasa, S., Skaareb, B., Gunnar, F. Validation of a FAST Model of the Statoil-Hywind Demo Floating Wind Turbine. 13th Deep Sea Offshore Wind R\&D Conference, EERA DeepWind'2016, 20-22 January 2016, Trondheim, Norway

30-C. M. Wang, T. Utsunomiya, S. C. Wee \& Y. S. Choo. Research on floating wind turbines: a literature survey. The IES Journal Part A: Civil \& Structural Engineering, Vol. 3, No. 4, November 2010, 267-277.

31-Floating Offshore Wind: Market and Technology Review. Prepared for the Scottish Government June 2015.

32-FLOATGEN IS FRANCE'S FIRST OFFSHORE WIND TURBINE. (https://floatgen.eu/sites/default/files/pdf/plaquette-floatgen_15x21_web.pdf)

33- Seif Bayoumi, Atilla Incecik and Hassan El-Gamal. Dynamic modelling of Spar-Buoy oscillating water column wave energy converter. Ships and Offshore Structures Journal, 2014, http://dx.doi.org/10.1080/17445302.2014.942086.

34-Offshore Renewable Energy. Proceedings of the 20th International Ship and Offshore Structures Congress, (ISSC 2018), Volume II,(doi:10.3233/978-1-61499-864-8-193).

35- Nadia Ashra and Islam Amin. Hybrid Floating Power Station driven by Renewable Energy for Saudi Arabia Coastal Areas. International conference on Electrical, Communication and Computer Engineering, ICECCE 2020, 12-13 June, 2020. (ISBN: 978-1-7281-7115-9). 